SHORT REPORT

\title{
Efficacy of screening the intermediate cluster region of the bcl2 gene in follicular lymphomas by PCR
}

\section{P J Batstone, J R Goodlad}

J Clin Pathol 2005;58:81-82. doi: 10.1136/jcp.2004.018135

\begin{abstract}
Background: The $t(14 ; 18)$ translocation is a common finding in nodal follicular B cell lymphomas and diffuse large B cell lymphomas, and results in the overexpression of the antiapoptotic bcl 2 protein. This chromosome rearrangement can be detected by the polymerase chain reaction (PCR), with most breakpoints in the bol2 gene occurring within either the major breakpoint region $(\mathrm{mbr}$ ) or the minor cluster region (mcr). However, recent investigations have revealed several breakpoints between these two regions, which cluster $19 \mathrm{~kb}$ $3^{\prime}$ of mbr in the "intermediate cluster region" (icr).

Aims/Methods: To analyse a series of 57 B cell follicular lymphomas known to carry the $t(14 ; 18)$ by PCR with primers directed against all three cluster regions to determine the efficacy of screening the icr site.

Results: Twenty six samples had an mbr rearrangement, four an mcr rearrangement, and three an icr rearrangement.

Conclusions: These results suggest that screening for icr is at least as efficacious as screening for mcr rearrangements.
\end{abstract}

$\mathrm{T}$ he $\mathrm{t}(14: 18)(\mathrm{q} 32 ; \mathrm{q} 21)$ translocation is a common finding in nodal B cell lymphomas of follicular morphology and to a lesser degree in diffuse large B cell lymphomas. At the molecular level, the bcl2 gene on chromosome 18 is brought adjacent to one of the immunoglobulin heavy chain gene $(\mathrm{IgH})$ joining regions $(\mathrm{JH})$ on chromosome 14. This results in bcl2 coming under the control of the $\operatorname{IgH} \mathrm{E} \mu$ enhancer, and overexpression of the antiapoptotic bcl2 protein ensues. The subsequent suppression of cell death is thought to enable the accumulation of other genetic lesions, which in turn leads to uncontrolled cell proliferation and progression to lymphoma.

"The $t(14: 18)(q 32 ; q 21)$ translocation is a common finding in nodal $B$ cell lymphomas of follicular morphology and to a lesser degree in diffuse large B cell lymphomas"

PCR analysis of the $t(14 ; 18)$ translocation is possible using primers directed towards the IgH JH and the bcl2 gene. Most chromosome 18 breakpoints occur in a cluster region 150 bp long in exon 3 of the bcl 2 gene, termed the major breakpoint region (mbr). ${ }^{1} \quad$ A second minor cluster region (mcr), approximately $500 \mathrm{bp}$ in length, is located $30 \mathrm{~kb}$ downstream. ${ }^{2}$ Recently, there have been several reports using long distance and inverse polymerase chain reaction (PCR) that have revealed additional breakpoints occurring between these two cluster regions. ${ }^{3}$ This region has now been sequenced and primers designed to detect $t(14 ; 18)$ rearrangements with breakpoints contained therein. ${ }^{5}$ It too contains a $200 \mathrm{bp}$ cluster region $19 \mathrm{~kb} 3^{\prime}$ of mbr, called the "intermediate cluster region" (icr).

\section{METHODS}

A series of 57 B cell follicular lymphomas cytogenetically known to harbour the $\mathrm{t}(14 ; 18)$ translocation (55 cases) or rearrangement of $14 \mathrm{q} 32$ (one case) or 18q21 (one case) were screened using our own standard PCR protocols to determine the efficacy of analysing the icr. Crude DNA extracts were produced by proteinase $\mathrm{K}$ digestion of fresh lymph node tissue. PCR amplification was carried out using a "hot start" technique and primer pairs comprising a consensus primer to $\mathrm{JH}$ and one of three different primers homologous to sequences in the mbr, ${ }^{1} \mathrm{mcr}^{2}$ or icr regions of bcl2 (table 1 ). Each reaction volume of $25 \mu \mathrm{l}$ contained $1 \times$ PCR buffer IV, $0.4 \mathrm{U}$ Thermoprime+ Taq polymerase, $0.15 \mathrm{mM}$ of each nucleotide, $1.5 \mathrm{mM} \mathrm{MgCl} 2$ (all ABgene, Epsom, Surrey, UK), $10 \mathrm{pM}$ of each primer, and $1 \mu \mathrm{l}$ of extracted DNA. After an initial five minute denaturation step at $98^{\circ} \mathrm{C}$ the enzyme was added. Thirty cycles were performed (denaturation at $94^{\circ} \mathrm{C}$ for one minute, annealing and extension at $60^{\circ} \mathrm{C}$ for 1.5 minutes), followed by a final extension step at $72^{\circ} \mathrm{C}$ for seven minutes. Positive and negative controls were included in each PCR assay; the positive control comprised a nodal follicular lymphoma with known $\mathrm{t}(14 ; 18)$. The final products were visualised by means of ultraviolet illumination of ethidium bromide stained polyacrylamide gels.

\section{RESULTS}

Of the 57 samples analysed, 33 yielded a single monoclonal band indicative of a $\mathrm{t}(14 ; 18)$ translocation. Of these, 26 exhibited rearrangement of the bcl2 major breakpoint region. A further four samples were shown to have a rearrangement of the bcl 2 mcr and three samples a rearrangement involving the bcl2 icr (fig 1 ). The two cases where no overt $t(14 ; 18)$ was present, but which contained rearrangements of $14 \mathrm{q} 32$ or 18q21, were monoclonal for an icr and mbr rearrangement, respectively. Mcr and icr PCR products were confirmed by sequence analysis (Cytomyx, Cambridge, UK).

\begin{tabular}{lll} 
Table 1 & Polymerase chain reaction primers & \\
\hline Primer & Sequence $\left(\mathbf{5}^{\prime} \rightarrow \mathbf{3}^{\prime}\right)$ & $\begin{array}{l}\text { Product size } \\
\text { range (bp) }\end{array}$ \\
\hline UH & TGA GGA GAC GGT GAC C & $80-300$ \\
mbr & GAG TG TAC GTG GCC TG & $500-700$ \\
mcr & CGC TTG ACT CCT TTA CGT GC & $75-300$ \\
s-icr & TCG TC TCA GTA AGT GAG AGT GC & TCA A \\
\hline
\end{tabular}

$\mathrm{UH}$, consensus primer to the immunoglobulin heavy chain gene joining regions; mbr, major breakpoint region primer; $\mathrm{mcr}$, minor cluster region primer; $s$-icr, intermediate cluster region primer.

Abbreviations: icr, intermediate cluster region; IgH, immunoglobulin heavy chain gene; $\mathrm{JH}$, joining region; mbr, major breakpoint region; $\mathrm{mcr}$, minor cluster region; PCR, polymerase chain reaction 


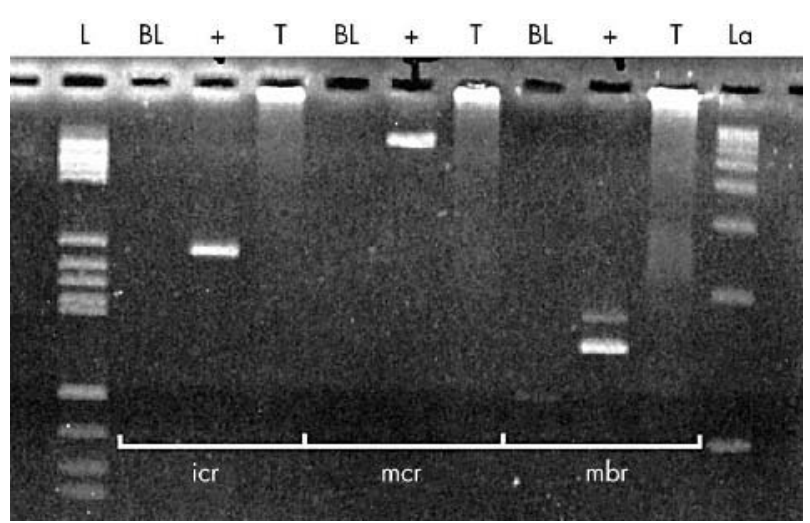

Figure 1 Polymerase chain reaction gel illustrating positive control samples (+) for major breakpoint region (mbr), minor cluster region $(\mathrm{mcr})$, and intermediate cluster region (icr) bcl2 rearrangements and a negative test (T) sample. BL, negative control lanes; $L$ and La, DNA size ladders (pBR322/haelll and 100 bp ladder, respectively).

\section{DISCUSSION}

The results of our small study suggest that screening of the intermediate region between mbr and mcr of the bcl2 gene can detect several $t(14 ; 18)$ rearrangements that currently go unnoticed with protocols involving primers directed only towards the mbr and mcr. We found three rearrangements within the intermediate region, a similar number to that seen with the use of mcr primers. Finding positive PCR products in samples with rearrangements of $14 \mathrm{q} 32$ and $18 \mathrm{q} 21$ suggests that cryptic or complex $t(14 ; 18)$ rearrangements are present in these cases.

"Our results indicate that screening of the intermediate cluster region with just one primer set is at least as efficacious as screening for minor cluster region rearrangements"

Because we have a mixed referral pattern of both fresh and paraffin wax embedded tissue samples we confined ourselves to our standard PCR technique supplemented with the s-icr primer, which has been designed specifically by AlbingerHegyi et al to allow analysis of the low molecular weight DNA fragments that formalin fixed tissue yield. ${ }^{5}$ Although we did not find three times as many icr as mor breakpoints, as reported by Albinger-Hegyi and colleagues ${ }^{5}$ using a combination of PCR techniques and primers, our results indicate that screening of the icr with just one primer set is at least as efficacious as screening for mcr rearrangements. If resources were available, more detailed analysis of the region between mbr and mor but outside of icr would yield an even greater number of $(14 ; 18)$ translocations.

The recently described BIOMED 2 primer sets published by van-Dongen et al also contain a primer $\left(5^{\prime} \mathrm{mcr}\right)$ covering the intermediate region. ${ }^{6}$ However, direct comparison between their findings, those of Albinger-Hegyi et al, ${ }^{5}$ and our results is complicated by the fact that different primer sequences and techniques are used. Nonetheless, it is interesting to note that Van-Dongen and colleagues ${ }^{6}$ found twice as many mor

\section{Take home messages}

- We analysed 57 B cell follicular lymphomas known to carry the $t(14 ; 18)$ by the polymerase chain reaction (PCR) with primers directed against the major breakpoint region $(\mathrm{mbr})$, the minor cluster region $(\mathrm{mcr})$, and the more recently identified "intermediate cluster region" (icr)

- These rearrangements result in the overexpression of the anti-apoptotic bcl2 protein

- Twenty six samples had an mbr rearrangement, four an mcr rearrangement, and three an icr rearrangement, suggesting that screening for icr is at least as efficacious as screening for mcr rearrangements

positive cases ( 11 of 109) as $5^{\prime}$ mcr positive cases (five of 109), which is in complete contrast to the findings of Albinger-Hegyi et al. ${ }^{5}$ It should also be borne in mind that the total number of $\mathrm{s}$-icr $/ \mathrm{mcr} / 5^{\prime} \mathrm{mcr}$ positive cases in all these reports remains small, and therefore further studies using these and other primer sequences will be required to determine the optimum combination of primers for detecting gene recombinations in the icr. For those cases that remain negative by PCR, it may be useful to use fluorescence in situ hybridisation techniques to maximise the detection of $\mathrm{Bcl} 2 /$ $\mathrm{IgH}$ rearrangements in the diagnostic setting.

\section{Authors' affiliations}

P J Batstone, J R Goodlad, Pathology Department, Highland Acute Hospitals NHS Trust, Raigmore Hospital, Inverness IV2 3UJ, UK

Correspondence to: Mr P Batstone, Pathology Department, Highland Acute Hospitals NHS Trust, Raigmore Hospital, Inverness IV2 3UJ, UK; paul.batstone@raigmore.scot.nhs.uk

Accepted for publication 25 August 2004

\section{REFERENCES}

1 Cleary ML, Sklar J. Nucleotide sequence of a $t(14 ; 18)$ chromosomal breakpoint in follicular lymphoma and demonstration of a breakpoint cluster region near a transcriptionally active locus on chromosome 18. Proc Natl Acad Sci U S A 1985;82:7439-43.

2 Cleary ML, Galili N, Sklar J. Detection of a second $t(14 ; 18)$ breakpoint cluster region in human follicular lymphomas. J Exp Med 1986;164:315-20.

3 Akasaka T, Akasaka H, Yonetani N, et al. Refinement of the BCL2/ immunoglobulin heavy chain fusion gene in $\mathrm{t}(14 ; 18)(\mathrm{q} 32 ; \mathrm{q} 21)$ by polymerase chain reaction amplification for long targets. Genes Chromosomes Cancer 1998;21:17-29.

4 Willis TG, Jadayel DM, Coignet $\amalg$, et al. Rapid molecular cloning of rearrangements of IGHJ locus using long distance inverse polymerase chain reaction. Blood 1997;90:2456-64.

5 Albinger-Hegyi A, Hochreutener B, Abdou M-T, et al. High frequency of $t(14 ; 18)$-translocation breakpoints outside of major breakpoint and minor cluster regions in follicular lymphoma. Am J Pathol 2002;160:823-32.

6 van-Dongen JJM, Langerak AW, Bruggermann M, et al. Design and standardization of PCR primers and protocols for detection of clonal immunoglobulin and T-cell receptor gene recombinations in suspect lymphoproliferations: Report of the BIOMED-2 Concerted Action BMH4CT98-3936. Leukemia 2003;17:2257-317. 